\title{
uma leitura histórica/ \\ literária para a sala de aula da obra A Retirada da Laguna de Visconde de Taunay
}

\author{
Elisa Maria Balzan" \\ Neimar Machado de Sousa**
}

Este artigo é parte de uma pesquisa desenvolvida no curso de Mestrado em Educação da Universidade Católica Dom Bosco (UCDB), na Linha 3 - Diversidade Cultural e Educação Indígena, sobre a criação da diferença na obra A retirada da Laguna, do autor Visconde de Taunay. Com base nesta pesquisa e com as informações obtidas da análise bibliográfica, nosso objetivo é investigar como os índios foram apresentados por Taunay, em sua obra. $\mathrm{O}$ poder era representado pelo autor, que, de família européia, mostrou-nos em seus relatos, sua experiência nos campos de guerra (Taunay foi membro do comando da expedição que invadiu o Paraguai durante a guerra de 1864 a 1870), que serão utilizados aqui como uma leitura didática, ao invés do livro didático tão discutido hoje, investigaremos os textos de Taunay e as
Os cadáveres paraguaios não arrastados a laço por seus compatriotas foram encontrados, todos eles, horrivelmente mutilados. O coronel censurou com violência os índios que haviam cometido tal profanação, ameaçando-lhes inclusive com a pena capital, se doravante desrespeitassem outra vez os mortos: foram tais a indignação e o temor que inspirou nos selvagens, que ficamos livres de semelhante espetáculo, até o final da campanha ${ }^{1}$. oda obra literária transcende o imaginário, pelo menos esta é a

* Elisa Maria Balzan - é formada em Letras Português/Inglês pela UNIDERP; Pós-graduada pela Estácio de Sá de Campo Grande em Metodologias de Linguagens Clássicas e Mestranda em Educação pela UCDB. E-mail: isabalzan@gmail.com

** Neimar Machado de Sousa - Graduado em Filosofia pela UCDB é Mestre em História Regional pela Universidade Federal de Mato Grosso do Sul e Doutor em Educação pela Universidade Federal de São Carlos. E-mail: professor_neimar@hotmail.com Educação pela UCDB. E-mail: isabalzan@gmail.com

${ }^{1}$ TAUNAY, Alfredo d'Escragnolle. 1843 - 1899. A Retirada da Laguna: episódio da Guerra do Paraguai. Trad. E organização de Sérgio Medeiros. São Paulo: Cia. das Letras, 1997, p. 125. 
informações a respeito dos indígenas. A metodologia consiste na tentativa de capturar os diálogos que se apresentam nesses relatos, formar uma discussão acerca da diferença que é projetada nos mesmos imergindo e procurando respostas, em como se poderia criar um espaço de leitura na sala de aula, nos dias atuais. Colheremos as informações dos textos de Taunay sobre os povos indígenas, na abordagem da diferença exibida ou omitida pelo autor, interligando com a construção de novos conceitos, permeando novas discussões e como recurso formador, produzindo novos conhecimentos. As leituras dos povos indígenas, levadas para a sala de aula, quando resultado da apreensão pela interpretação de uma obra literária como o é A retirada da Laguna, e como parte da História é sem dúvida nosso desafio, na tentativa de cotejar com educadores e teóricos das áreas dos Estudos Culturais e da Educação.

Palavras- chave: Indígenas; Visconde de Taunay; A retirada da Laguna; educação; diferença.

This article is part of a research carried out in the course of Masters in Education from $\mathrm{Ca}$ tholic University Dom Bosco (UCDB), Line 3 - Cultural Diversity and Indigenous Education, about the creation of the difference in the work Withdrawal from Laguna, the author Viscount Taunay. Based on this research and the information obtained from literature review, we aim to investigate how the Indians were presented by Taunay in his work. The power was represented by the author, that of European family, showed us their stories, their experience in the fields of war (Taunay was a member of the command of the expedition to Paraguay invaded during the war from 1864 to 1870), which will be used here as a didactic reading, instead of the textbook as discussed today, investment garemos Taunay texts and information about the Indians. The methodology consists in the attempt to capture the dialogues that appear in these reports, form a discussion about the difference that is designed and immersing ourselves looking for answers on how we could create a reading space in the classroom today. Reap information from texts Taunay on indigenous peoples, in addressing the difference as displayed or omitted by the author, connecting with the construction of new concepts, new discussions and permeating as a resource trainer, producing new knowledge. The readings of indigenous peoples, brought to the classroom when the result of apprehension by the interpretation of a literary work is like The withdrawal of Laguna, and as part of our history is undoubtedly challenging, in an attempt to collate with educators and theorists of areas of Cultural Studies and Education.

Keywords: Indians; Viscount Taunay; Withdrawal of Laguna; education; difference.

imagem que, no primeiro momento obtemos. Na obra $A$ retirada da Laguna de Visconde de Taunay, publicada originalmente em língua francesa (1871), não poderia ser diferente.

Ítalo Calvino em seu ensaio intitulado Por que Ler os Clássicos ${ }^{2}$ reforça a perspectiva da leitura/ releitura das obras consideradas clássicas, pois, a cada releitura abrem-se novas descobertas tal qual a primeira. Um clássico é um livro que nunca terminou de dizer aquilo que tinha para dizer, sob esse aspecto, caracteriza-se pelo alto teor de inesgotabilidade. Com essa perspectiva pensamos em produzir esse estudo, apresentado aqui e que propõe a leitura dessa obra tão

${ }^{2}$ CALVINO, Ítalo. Por que ler os classicos. São Paulo: Cia. das Letras, 1994. 
instigante, com uma proposta literária, voltados para a História. Mesmo sabendo que a obra $A$ retirada é-nos apresentada em relatos aos quais Santos ${ }^{3}$ aponta como "relatos de guerra" ou "relatos de viagem", a obra trata dos sujeitos presentes na Guerra do Paraguai de forma literária, porém percebemos pelas imagens triunfalistas que Taunay nos apresentou os índios, como meros serviçais a mando da Pátria comparando-os com os selvagens paraguaios, o cruel inimigo. É importante que entendamos: “o substantivo masculino 'relato' vem do latim relãtus, que reconhece a relação, a descrição e a noticia sobre algo ou alguém" Santos considera ainda, que existe um poder que transcende a forma linguística e que aparece nos relatos de viagens, permeando sentidos que legitimam as formas várias de ver o mundo.

[...] vemos no relato de guerra, que também é um relato de viagem, A retirada da Laguna, de Taunay, a negação do outro como sujeito capaz de expressar uma civilidade, isto é, um modo de se portar em face do mundo. No caso, esse sujeito é o paraguaio e também os índios brasileiros que acompanhavam a expedição brasileira ${ }^{5}$.

Entendemos então que o índio aparece nos relatos como o selvagem, o cativo, o homem primitivo e cruel, pois, para o modelo europeu que legitimava as vozes de Taunay, como em: “... quanto lhes foi possível, de conter o legitimo desforço de bizarros soldados, exasperados pelo furor do inimigo, e obstar à crueldade tradicional de auxiliares índios, vingativos como soem ser"6 nos perguntamos: esse olhar do autor legitima qualquer forma de exclusão implantada aos "selvagens"? Foram-lhe justificados os atos de crueldade e violência, quando pensarmos, o que para Taunay é um ato de selvageria para os índios não seria uma representação de sua cultura?

Qualquer forma de violência Taunay apontou aos paraguaios e aos índios. A negação da violência pelos soldados brasileiros parece-nos uma tácita forma de calar o discurso etnocêntrico. O homem é capaz de ser "[...] gerador de discri-

\footnotetext{
${ }^{3}$ SANTOS, R. C Z. De memórias, de fronteiras, de viagens e de violência em A retirada da Laguna. In; ESTEVES, A. R., ZANOTO, S. A. (orgs.). Literaturas de viagem, viagens na literatura. Assis: Triunfal Graf. e Ed., 2010.

${ }^{4}$ Idem, p. 250, grifo do autor.

${ }^{5}$ Idem, p. 250/1, grifo do autor.

${ }^{6}$ TAUNAY, Alfredo d'Escragnolle. A retirada..., op. cit., p. 38.
} 
minações étnicas e raciais para justificar diferenças e diversidades de populações que passam a ser classificadas como nativas, aborígenes e tribais" ". Entendemos que ao proceder assim o jovem Taunay por alguma razão que tentaremos descobrir ao longo da investigação, negou as identidades culturais dos índios e veremos de que maneira apresentou-nos a exclusão, no texto.

No século XIX, os índios se subdividiam em bravios e mansos, como cita Manuela Carneiro da Cunha8, "Há primeiro os Tupi e os Guarani [...]. É o índio que aparece como emblema da nova nação em todos os monumentos,[...] É o caboclo nacionalista da Bahia, é o índio do romantismo na literatura e na pintura. É o índio bom e, convenientemente, é o índio morto.” E ainda cita o chamado Botocudo, conhecido como indomável. Os aldeamentos que se iniciaram no período colonial transformaram o comportamento dos índios: o índio bom era aquele que aceitava calmamente o aldeamento, o índio revoltoso era o que se preso ou aldeado, só o seria a revelia. Normalmente fugia antes de ser aldeado, era perseguido e morto, pois era considerado violento pela razão que não se submeteu às ordens do homem não índio.

Eleger a etnia como uma das categorias em educação significa entender que o pertencimento étnico, enquanto uma concreção ou singularização do cultural numa especificidade própria tem uma dimensão engendradora das potencialidades específicas de grupos no conjunto do processo histórico9 ${ }^{9}$.

As imagens triunfalistas que Taunay nos revelou, surgem como estereótipos pré-moldados em que as reminiscências da guerra urgiram brotar. Elas estão presentes, nos vários formatos linguísticos, nas narrativas apologéticas que derivam de um "olhar" pedante em relação ao homem cru da terra, o homem primitivo esculpido pelo olhar do autor de forma dissonante da sua visão aos demais membros do grupo. Nas narrativas apologéticas, o soldado e os homens do comando da expedição são mencionados como atos heróicos em que se leia dos textos do autor, apenas o bom soldado, herói e complacente até com o inimigo em alguns

${ }^{7}$ FLORES, Elio Chaves. Etnicidade e Ensino de História: a matriz cultural africana. In: Nós e Eles: etnia, etnicidade, etnocentrismo. Rio de Janeiro: Tempo. № 21. Departamento de História da Universidade Federal Fluminense, 2006, p. 6.

${ }^{8}$ CUNHA, M. Carneiro da. Núcleo de História Indígena e do Indigenismo. In: Política Indigenista do Século XIX. São Paulo: Schwarcz, 2008.

${ }^{9}$ KREUTZ, Lúcio. Identidade Étnica e Processo Escolar. Associação Nacional de Pós-Graduação e Pesquisa em Ciências Sociais - ANPOCS - XXII Encontro Anual Caxambu - MG. 1998, p. 3. 
feitos, constituído de bom senso e de uma genética de força e sensatez, honra e méritos por defender sua honrada pátria. Os deméritos eram todos para o inimigo e os índios.

Até que Taunay conheceu Antônia. Uma linda jovem da tribo dos Chané que mudou seu "olhar" sobre os índios. Ao tentar conquistar a moça, Taunay aproximou-se dos Terena a ponto de nas Memórias ${ }^{10}$ mencionar inúmeras passagens em que fala desse convivência pacifica entre os membros da equipe e os índios, em especial dele mesmo.

Portanto, retornamos à busca de compreendermos como se passou o processo histórico, se não de forma completa, mas como uma tentativa de refletirmos sobre o engajamento de Taunay. A obra A retirada da Laguna retrata a retirada da Laguna episódio da Guerra do Paraguai ou Guerra da Tríplice Aliança, que se iniciou no território brasileiro e culminou com a invasão do Paraguai, de 1864 a 1870. O autor Alfredo Maria Adriano d'Escragnolle Taunay, o Visconde de Taunay, nasceu em 22 de fevereiro de $\underline{1843}$ na cidade do Rio de Janeiro e morreu em 25 de janeiro de 1899 com 55 anos. Taunay era escritor, professor, político, historiador e sociólogo nascido em uma família aristocrática de origem francesa, e filho de Félix Emílio Taunay, pintor e professor da Academia Imperial de Belas Artes, e sua mãe, Gabriela Hermínia Robert d' Escragnolle Taunay, irmã do Barão d' Escragnolle.

Em 1864, ao iniciar a Guerra do Paraguai, Alfredo Taunay integrou-se à coluna expedicionária para defender o território nacional contra o plano paraguaio encampado pelo ditador Francisco Solano López. Na guerra, Taunay participou como engenheiro militar, de 1864 a 1870, experiência que resultou em seu livro A retirada da Laguna, considerada sua obra mais conhecida e importante, pela riqueza de seus relatos e pelas informações estudas ao longo de séculos por pesquisadores não só da história da guerra, como também das questões que identificam e analisam o ser humano e seus comportamentos sociais.

Taunay ocupava um lugar confortável junto aos componentes da guerra, por representar a monarquia, representava o poder. Os relatos apresentados pelo

${ }^{10}$ TAUNAY, Visconde de. Memórias. São Paulo: Iluminuras; 592 páginas, 1948. 
autor ao longo da guerra e enviados ao Imperador para informar dos acontecimentos nos campos de batalha tornaram-se parte da obra que é aqui estudada.

Não se pretende aqui formar conceitos críticos sobre a obra $A$ retirada, apenas procurar-se-á discutir a maneira como o autor aborda a presença indígena, em seus relatos e como os apresenta ao leitor. O objetivo é questionar como ultrapassar as fronteiras da literatura propriamente dita e transcender pelas imagens históricas, triunfalistas, que o autor criou, para apresentar conotações do poder, por ele representado. Ainda na leitura da obra, pensamos em refletir sobre os textos em que as impressões do autor surgem sobre os índios na guerra, e de que forma poderiam ser utilizados em sala de aula para produzir conhecimento.

É importante que, ao iniciar este estudo, partamos do inconteste jogo de interesse que a guerra formou, mesmo ao que a ela deu origem, como citou Taunay:

Em 1865, no início da guerra que o presidente do Paraguai López, ${ }^{11}$ sem outro motivo que a ambição pessoal, suscitara na América do Sul, mal amparado no vão pretexto de manter o equilíbrio internacional, o Brasil, obrigado a defender sua honra e seus direitos, dispôs-se resolutamente à luta. A fim de enfrentar o inimigo nos pontos onde fosse possível fazê-lo, ocorreu naturalmente a todos o projeto de invadir o Paraguai pelo norte; ${ }^{12}$.

Pensamos: Taunay justificou a invasão do território vizinho pelo fato de que suas divisas foram ameaçadas pelo governo López, por pensar em alargar as fronteiras do seu país, movido simplesmente pela ambição pessoal, como comentou Taunay em $A$ retirada da Laguna $^{13}$. E refletimos como se mostrou o homem que habitava essa região, e como transportamos nossa discussão acerca da territorialidade, das fronteiras desses povos excluídos em suas origens e "jogados" em parte alguma, contrariando o pertencimento tão inerente às formações culturais dos povos indígenas. Mas, estes, convencidos pelo não índio, "mergulham" nos campos de guerra, não empunhando armas, mas carregando-as, ven-

\footnotetext{
${ }^{11}$ Francisco Solano López (1826- 1870) era filho do ditador Carlos Antonio López, que governou o Paraguai entre 1840 e 1862 . Foi educado no Paraguai e na Europa e, ao retornar ao seu país, passou a colaborar com o pai, tornando-se logo ministro da Guerra e da Marinha. Subiu ao poder em 1862. Em 1867, foi morto por tropas brasileiras. In: TAUNAY, Alfredo d'Escragnolle. A retirada... op. cit., p. 38 .

${ }^{12}$ Idem, p. 37.

${ }^{13}$ Idem.
} 
cendo os desatinos da fome, da miséria, da perda da terra e consequentemente de sua identidade.

Quando falamos em identidade pensamos que as culturas são processos identitários, os quais também conflitivos:

A identidade étnico-cultural não é uma realidade muda, ela é fonte de sentido e de construção do real, mesmo onde aparece como marginalizada. [...] Isto significa que a etnia, isto é, o pertencimento étnico em processo, concorre na constituição de sujeitos e de grupos. É um elemento constituinte de práticas sociais, e ao mesmo tempo as práticas sociais vão constituindo a reconfiguração étnica. Entendo, com Scott (1990), que tanto o gênero quanto o étnico perpassam os símbolos de uma sociedade, suas normas, sua educação, sua organização social. Isto significa que a educação é etnicizada, 'atravessada' pela etnia. O étnico é elemento de diferenciação social, influi na percepção e na organização da vida social. Ele não se dá no abstrato. Manifesta-se nos símbolos, nas representações e nas valorações de grupos. $\mathrm{O}$ étnico concorre para que a concreção histórica se efetive de uma forma específica ${ }^{14}$.

Percebemos então, nas palavras de Kreutz, que o processo cultural é sempre um processo conflitivo, ainda pondera “...o tema do racismo não é apenas um 'companheiro de viagem da exploração colonial', legitimando-a, mas também constitui um paradigma profundamente vinculado com as lutas nacionalistas que acabaram desembocando nas duas Guerras Mundiais"15.

E afirma: "O projeto educacional foi articulado, na modernidade, com este modo de compreender a sociedade. Ele é, a exemplo da literatura, o resultado de um longo e contínuo processo de uma forma de expressão nacional", complementa Kreutz ${ }^{16}$, que esse processo apontou a hierarquia como supremacia e o nacional, excluído. " A escola, tal como foi implementada na formação dos Estados Nacionais, faz parte e foi um dos 'instrumentos privilegiados' que levaram à interiorização da idéia de que estes conhecimentos tratados numa perspectiva generalizante são superiores aos saberes particulares e locais"'17.

\footnotetext{
${ }^{14}$ KREUTZ, Lúcio. Op. cit., p. 2, - grifo do autor.

${ }^{15}$ Idem, p. 10.

${ }^{16}$ Idem, p. 13.

${ }^{17}$ Idem.
} 
Desse modo entendemos como Backes ${ }^{18}$ escreve: "Entender que os significados culturais regulam normativamente a vida do sujeito requer a compreensão de como as normas operam. O estudante, no espaço escolar, está dentro de um conjunto de normas que ele compartilha com os demais". E compreendermos de que a cultura não é um conjunto de produtos acabados, que podem ser transmitidos de um/uns para outro/outros, "ao contrário, a cultura é um trabalho de produção, invenção, criação, construção" e conclui: "A cultura é prática de significação, é prática produtiva, é uma relação social, é uma relação política (de poder), é produtora de identidades e diferenças"19.

Fizemos esse "recorte" na abordagem da vida escolar do indivíduo, para comentarmos como se constrói as relações sociais, e que dentro da escola elas produzem significados. São sempre produtos de representações, estão articuladas com relações de poder, complementa Backes ${ }^{20}$.

Assim, ao se promover a escolarização, na modernidade, sob o movimento de formação dos Estados Nacionais, esta mesma escolarização tem se tornado fortemente um fator de imposição da língua nacional e do desaparecimento de falas locais e de dialetos ${ }^{21}$.

A escola trás consigo especificidades que cada escola contém. A cultura escolar é o que a escola trás/tem e que deve prezar para passar para o aluno. Mas, as políticas nas sociedades são marcadas por desigualdades e exclusões, como os grupos mais excluídos, como mulheres, índios, afro-descendentes e, portanto é imprescindível o trabalho de conscientização, pois, "não há educação que não esteja imersa na cultura da humanidade e particularmente, do momento histórico e do contexto em que se situa" ${ }^{22}$.

Há uma política, uma poética e uma filosofia da diferença. Mas, como descrever essas questões sem inventar novamente o outro, sem massacrá-lo, sem

\footnotetext{
${ }^{18}$ BACKES, J.L. Cultura, representação, linguagem e poder. In: A negociação das identidades/ diferenças no espaço escolar.São Leopoldo:UNISINOS, 2005, p. 4.

${ }^{19}$ Idem.

${ }^{20}$ Idem.

${ }^{21}$ KREUTZ, Lúcio. Op. cit., p. 4.

${ }^{22}$ CANDAU, Vera Maria. O educador/a como agente cultural. In: LOPES, Alice Ribeiro Casimiro; MACEDO, Elizabeth Fernandes de; ALVES, Maria Palmira Carlos (Org.). Cultura e política do curriculo. Araraquara, SP: Junqueira \& Martin, 2006, p. 39.
} 
designá-lo, sem emudecê-lo, sem deixá-lo tenso na fixação do diferente, sem constituí-lo em um simples ventrículo de nossa mesmidade ${ }^{23}$, sem transformá-lo em uma espacialidade exterior de nossa (in)diferença? ${ }^{24}$.

Pois o outro que se apresenta diante de "nós", não necessariamente é aquele que ocupa outro lugar no mundo, mas Skliar nos provoca com o questionar de que, quem é, afinal, o outro? E discorre: “...não é uma pergunta cuja resposta possa nos conduzir à confortável e tranqüilizadora conclusão de que todos somos, de certo modo, outros ou então todos somos, de certo modo, diferentes" 25 . Ao que podemos concluir: as diferenças existem, não é questão de hierarquizá-las, mas de entender como compreendê-las.

Candau ${ }^{26}$ também aborda o daltonismo cultural presente nas escolas, o daltonismo escolar dos professores, do pensamento e comportamento padrão, quando se tende a naturalizar a multiculturalidade e não a questiona, nem a trata como um desafio para a educação.

E aborda:

Para ensinar é necessário ter certezas e uma maneira de apropriação dos conhecimentos disponíveis na sociedade que nos permitam fazer afirmações absolutas e universais, que nos dêem segurança e também favoreçam a aquisição por parte dos alunos e alunas de referenciais seguros, balizas firmes, onde as fronteiras entre as verdades e os erros possam ser claramente estabelecidas ${ }^{27}$.

Ao universalizar a educação nos prendemos a conceitos já estabelecidos, relativizando os modos de ser, as culturas, as diferentes visões de mundo, os conhecimentos adquiridos, as formações históricas e sociais dos alunos. Evitar esse procedimento possibilita-nos de praticar "uma dinâmica fundamental para

\footnotetext{
${ }^{23}$ Skliar (2003) define a mesmidade como sendo o centro vigiando e controlando o outro, conduzindo-o, mas que insiste ao mesmo tempo e no mesmo espaço, sobre as bondades e a perfeição de sua centralidade. A mesmidade leva à normalização e esta, à tríade modulação-controle-exclusão, que parece deslocar do cenário o binômio disciplinamento/inclusão. Dizer que todos somos de certo modo outros, ou então, todos somos de certo modo diferentes, não retira a mesmidade do centro.

${ }^{24}$ SKLIAR, Carlos. Pedagogia (Improvável) da Diferença. E se o Outro não estivesse aí? Rio de Janeiro: DP\&A, 2003. p. 143.

${ }^{25}$ Idem, p. 102.

${ }^{26}$ CANDAU, Vera Maria. Op. cit. .

${ }^{27}$ Idem, p. $47 / 8$.
} 
que sejamos capazes de desenvolver currículos coerentes com o multiculturalidade. Nessa perspectiva, trabalhar o cruzamento de culturas presentes na escola constitui também uma exigência que lhe está intimamente associada”, afirma Candau $^{28}$.

As multiculturas podem ser entendidas e compreendidas quando possamos perceber que as diferentes experiências promovem diferentes resultados imbricadas pelos recursos que os sujeitos utilizam na sua caminhada. Sendo assim aproveitemos as considerações que Candau nos apresenta:

Conceber o/a educador/a como uma agente cultural ainda constitui uma perspectiva somente anunciada em alguns cursos de formação inicial e/ou continuada de educadores/as. No entanto, essa concepção é fundamental se queremos contribuir para que a escola seja reinventada e se afirme como um lócus privilegiado de formação de novas identidades e mentalidades capazes de construir respostas, sempre com caráter histórico e provisório, para as grandes questões que enfrentamos hoje, tanto no plano local, quanto nacional e internacional. ${ }^{29}$.

Gomes ${ }^{30}$ atenta para o novo olhar sobre a escola e a forma como os processos sócio-culturais constroem ressignificados no processo da escola. O diálogo entre Educação e Cultura abre uma necessidade de se compreender e reconhecer como a sociedade e a escola estão interligadas pelo próprio espaço de diversidade que apresenta. Mas, quando o professor diz: em sala de aula todos os alunos são iguais, é o atropelo da diferença, é a presença da igualdade formal, na qual se esquece que os alunos não são iguais, pois têm suas necessidades diferentes e particulares. A diferença é vista como sinal de deficiência, de incapacidade, e por isso a reflexão aponta para a urgente necessidade de perceber que os sujeitos são formados pelos seus processos sociais e sua interação como essas relações representam o conhecimento que eles têm do mundo, contribui Gomes ${ }^{31}$.

A cultura tem um papel importante na vida dos sujeitos. Isso dá uma dimensão de conhecimento que os educadores não podem negar, em sala de aula, portanto, há necessidade de uma discussão no meio acadêmico educacional, para se

\footnotetext{
${ }^{28}$ Idem, p. 48, grifo do autor.

${ }^{29}$ Idem, p. 50.

${ }^{30}$ GOMES, N.L. Escola e Diversidade Étnico-Cultural: um diálogo possível. In: Múltiplos Olhares sobre educação e cultura. Juarez Dayrell (org.), Belo Horizonte: Editora UFMG, 2001.

${ }^{31}$ Idem.
} 
reelaborar um olhar mais aguçado e um posicionamento da escola ante as questões que afetam a cidadania e acarretam preconceitos. Questões étnico-raciais, de sexualidade, de gênero, racismo estão entre as que devem ser revistas e discutidas para se eliminar atitudes discriminatórias dentro da escola, cita Gomes ${ }^{32}$.

Brand $^{33}$ escreve que houve avanços significativos na educação básica, nas áreas indígenas, mas há poucos avanços em relação à aceitação por parte dos órgãos públicos sobre a escola diferenciada. Uma discussão que deve transpassar as barreiras do discurso, e o respeito à diferença garantida nos termos da lei, porém ainda prevalece o discurso hegemônico e colonial. Mesmo escolas com professores indígenas seguem em muitos casos, ensinando lições longe da realidade vividas pelos alunos indígenas. Na Constituição de 1988, encontram-se frisados dois aspectos importantes para esses povos: a autonomia, no qual engloba o reconhecimento das terras, o respeito a organização social dentre outros dispositivos e o conceito de diferenciado que é uma proposta de ensino inovador com respeito à liberdade e ao direito que cada povo pretende, cada conceito desses deve ser discutido frente as lutas de cada povo. Uma política indigenista autoritária que prevaleceu como modelo escolar durante décadas, deixou uma sequela histórica, embora a Constituição garanta o fortalecimento dessas culturas, há de se pensar numa forma de "quebrar as barreiras", a burocracia que impede a prática dessas ações de autonomia para os povos indígenas.

Novos espaços devem ser reavaliados para poder com isso contribuir para que a pesquisa possibilite instrumentos na produção do conhecimento privilegiando aos povos indígenas na construção de melhor qualidade de vida aos seus descendentes. O desafio é a sustentabilidade das populações envolvidas, sempre voltados ao desenvolvimento sem, contudo se perder o conhecimento e as novas tecnologias, usadas de forma responsável, para criar melhores condições de sustentabilidade e autonomia para as populações indígenas no Brasil, num conhecimento engajado e multicultural da sociedade brasileira, conclui Brand ${ }^{34}$.

\footnotetext{
${ }^{32}$ Idem.

${ }^{33}$ BRAND, Antonio. Indigenas no Ensino superior: experiências e desafios. Apresentado no $15^{\circ}$ COLE - 04 a 08 de julho de 2005 in Artigos eventos científicos COLE (in Desafios atuais da Educação Escolar Indígena Campinas: ALB, Núcleo de Cultura e Educação Indígena; Brasília: Ministério dos Transportes, Secretaria Nacional de Desenvolvimento do Esporte, 2005.
}

${ }^{34}$ Idem. 
É de fundamental importância à abordagem em torno da questão étnico/ cultural/racial, ressaltando a necessidade da desconstrução social do preconceito e da discriminação racial que são atribuídos à população negra e indígena. Deve-se suscitar reflexões sobre as representações sociais negativas colocadas a essas populações por meio de estigmas e estereótipos. Levantar o questionamento da educação étnico-racial no espaço escolar a partir da Lei Federal No 10.639 de 09 de janeiro de 2003, agora 11.645/08 que alterou a Lei de Diretrizes e Bases da Educação Nacional, Lei 9.394/96 estabelecendo a obrigatoriedade do ensino sobre História e Cultura Afro-Brasileira e indígena, nos estabelecimentos de ensino fundamental das escolas publicas.

Concluímos, ao entendermos nessas reflexões, que novos métodos de ensino devam ser pensados, criando novos diálogos e reflexões para o âmbito da escola, que as verdades possam ser questionadas e não mais vistas como absolutas, mas refletidas por conta das estruturas culturais/sociais dos partícipes. Que todos envolvidos na educação, sejam os educadores, nas pessoas dos professores, coordenadores, diretores e os demais dentro e fora da escola, os próprios alunos que hoje não se deixam "subornar" nas tentativas de padronizar as diferenças, muito pelo contrário, portadores de conhecimentos advindo das novas tecnologias, têm refletido sobre a sua condição no mundo, como o índio, hoje, muito mais presente nas discussões que envolvem as questões culturais, sociais e linguísticas que promovem tantas e tão desafiadoras discussões.

Giroux em seu texto Praticando estudos culturais nas faculdades de educação $0^{35}$ afirma que existe uma pedagogia em qualquer lugar em que o conhecimento é produzido. Neste caso a pedagogia crítica pode ser compreendida como um esforço ao qual produzirá identidades e suas práticas ideológicas e sociais.

É preciso compreender a cultura como uma luta em torno de se ler textos, não somente voltados para a ideologia. A discussão irá se formar acerca de duas questões: a pedagogia crítica da representação, enfatizando a noção de autoridade textual pelo professor, que "poda" o senso crítico do aluno combatendo a interpretação; e a pedagogia transformativa. Torna-se necessária uma pedagogia crítica de representação para desvelar a discursividade do conhecimento, que

\footnotetext{
${ }^{35}$ GIROUX, Henry A. Praticando estudos culturais nas faculdades de educação. In: SILVA, Tomaz Tadeu da (Org.). Alienígenas na sala de aula. Uma introdução aos estudos culturais em educação. Petrópolidz; Voxrd, 1995, p. 85-103.
} 
molda a existência social, bem como as economias de poder privilegiam arranjos sociais desiguais, afirmam Giroux e Maclaren, no texto Por uma pedagogia crítica da representação $o^{36}$.

Giroux $^{37}$ comenta que a pedagogia crítica da representação deve trazer estratégias para compreender o poder, as ideologias, a cultura e a política presentes na produção textual. A representação deve ser entendida como uma interpretação ética, que dê fundamento à relação eu versus outro em práticas que promovam a solidariedade e não a opressão. Na pedagogia transformativa pode-se criar uma política contra hegemônica que crie oportunidades para questionar o poder, as formas sociais e coletivas, numa reflexão crítica e repensar suas habilidades para promover uma transformação social.

A pedagogia como forma de produção cultural: os alunos devem cruzar fronteiras, as experiências em sala de aula para desenvolver habilidades e experiências emancipatórias e não alienantes. A escola e outras esferas devem ter um projeto em comum nas lutas políticas e pedagógicas, no contexto social e político mais amplo.

O educador dever ser como um trabalhador cultural deve ampliar ativamente os trabalhos além da escola, criando novas lutas democráticas e produzindo melhoras no planeta, à dignidade humana e à justiça social, conclui Giroux e Maclaren $^{38}$.

Silva $^{39}$ aponta duas grandes reflexões que os etnólogos brasileiros têm abordado nos últimos anos: de um lado o pensamento clássico do indígena mágico, selvagem, primitivo, etc.; e do outro, a questão da escolarização dos índios. A autora apresenta em sua discussão uma preocupação quando não ocorrem os diálogos. Se a questão é complexa e exige uma série de estudos e pesquisas, debates recentes abrem a discussão para o pensamento ameríndio e a possibilidade da construção de uma educação crítica e uma revisão crítica do papel da escola.

\footnotetext{
${ }^{36}$ GIROUX, Henry A.; MACLAREN, P. L. Por uma pedagogia crítica da representação.In: SILVA, Tomaz Tadeu da Silva; MOREIRA, Antonio Flavio (Org.). Territórios contestados. O currículo e os novos mapa politicos e culturais. 5ª ed. Rio de Janeiro: Vozes, 1995, p. 144 - 158.

${ }^{37}$ Idem.

${ }^{38}$ Idem.

${ }^{39}$ SILVA, Aracy Lopes da. Uma “Antropologia da Educação” no Brasil? Reflexões a partir da escolarização indígena. In: Aracy Lopes da Silva e Mariana Kawal Leal Ferreira (org.), Antropologia, História e Educação. A questão indígena e a escola, São Paulo: Global, 2001.
} 
Do pensamento ameríndio, os mitos chamaram a atenção dos estudiosos, as "categorias nativas" tidas como valores, pessoa, tempo, idiomas, corporalidade, a relação com a natureza e o mundo dos espíritos, abre-se um campo para estudos sobre esse "ser" diverso. Silva ${ }^{40}$ compreende que as relações sociais e seus universos são específicos de cada etnia: há uma subjetividade e um simbolismo que ganham dimensões na elaboração do conhecimento sobre as coletividades indígenas e de suas histórias; a própria relação com a morte é cultural e diferente em cada etnia.

As questões da educação indígena debatidas em inúmeros estudos, citados alguns pela autora, expõe amplo debate sobre a pesquisa e a antropologia, e Silva $^{41}$ comenta sobre a pesquisa ser uma reflexão da prática escolar indígena dentro dos direitos educacionais.

É o momento de impulsionar uma reflexão mais densa sobre o que deva ser a educação diferenciada e oferecer bases sólidas para os diálogos entre os índios e seus assessores, pois é urgente a consolidação de uma antropologia crítica escolar indígena - complementa a autora ${ }^{42}$.

Como esse estudo se propôs a estabelecer um diálogo entre a obra $A$ retirada e a sala de aula, o principal objetivo é de cotejar a literatura e a construção do conhecimento, num pleno engajamento, num espaço e lugar ocupados pelos construtores do conhecimento que são os docentes e discentes. Mas, ao mesmo tempo nos preocupamos em "de que modo" essa leitura será realizada. Engajando os diálogos, nosso primeiro "olhar", é em torno de uma escola que seja diferenciada e promissora, diferentemente daquela em que há uma constante apropriação dos valores exatos, universalizantes e dogmáticos, impostos pelos saberes tradicionais e como resquícios de uma escola colonizadora, a escola tradicional. Então, havemos de nos perguntar: como poderia ser conduzida a construção do conhecimento dessa mesma obra numa escola indígena, sendo que Taunay descontrói o índio em toda sua narrativa, tornando-o um membro serviçal e bruto, inconteste à sua condição e cultura?

Essas perguntas nos são provocações que surgem ao longo dessa reflexão, pois estão interligadas com o objeto da pesquisa em andamento no curso de

\footnotetext{
${ }^{40}$ Idem.

${ }^{41}$ Idem.

${ }^{42}$ Idem.
} 
Mestrado em Educação da UCDB, e que se propõe a analisar a obra $A$ retirada da Laguna, permeando um estudo bibliográfico sobre a criação da diferença nesta mesma obra, do autor Visconde de Taunay. Pensamos em entrelaçar essa construção com a sala de aula, traçando um diálogo entre a presença da diferença em que surge, aparece ou é omitida, principalmente em se tratando da questão indígena.

A busca pelas respostas continua. Não há resposta pronta e definitiva em termos de precisão, pois mesmo que completamente certos de nossa leitura da obra $A$ retirada, sempre havemos de considerar a existência de um outro olhar, advindo do outro, a considerar o outro diferente de "mim" que faz a sua leitura de mundo com outro olhar: o "seu" olhar. Um olhar que vem recheado de informações da realidade e dos conhecimentos que trás consigo e que constrói novas perguntas, resultando em novas respostas. Se novos olhares forem produzidos aqui e novos "pontos de interrogação" provocarem novas perguntas, nosso desafio foi lançado.

Estamos certos de que a escola comprometida com os saberes fundamentais que são as produções do conhecimento em torno e a partir de um prévio saber que todos portamos, poderá fundamentar e utilizar as obras como $A$ retirada $d a$ Laguna nas suas leituras, sendo uma parceria constituída de saberes históricos e literários profundos, mesmo que questionados, poderão ser uma provocação para o despertar de novos olhares. 
